\title{
Exploring the Use of Digital Technologies from the Perspective of Diverse Learners in Online Learning Environments
}

\author{
Alex Kumi-Yeboah and Yanghyun Kim \\ University at Albany, New York, USA \\ Anthony Mawuli Sallar \\ Ghana Institute of Management and Public Administration, Accra - Ghana \\ Lydiah Kananu Kiramba \\ University of Nebraska-Lincoln, Nebraska USA
}

\begin{abstract}
This qualitative study explored digital technologies that promote educational experiences and achievements of culturally diverse learners via interviews with 46 culturally and linguistically diverse students across different academic programs. A qualitative research design using semistructured interviews was used to collect the data for the study. The analysis of the data identified that digital technologies, multimedia presentations, and social network tools facilitate educational experiences and achievements of participants in asynchronous online learning environments. Participants applied digital technologies to navigate the Learning Management Systems (LMS) to engage and contribute to knowledge creation to achieve better academic success in online context. Findings support the need for online instructors to incorporate digital technologies to facilitate academic engagement and achievements of students from diverse backgrounds in online learning.
\end{abstract}

Keywords: digital technologies, diverse learners, constructivism, collaborative online learning, social network tools, multicultural content resources

Kumi-Yeboah, A., Sallar, A.W., Kiramba, L.K., \& Kim., Y. (2020). Exploring the use of digital technologies from the perspective of diverse learners in online learning environments. Online Learning, 24(4), 42-63. https://doi.org/10.24059/olj.v24i4.2323 


\section{Exploring the Use of Digital Technologies from the Perspective of Diverse Learners in Online Learning Environments}

Online education is inherently technology-based through information and communication technology (ICT) that has allowed humans to interact beyond temporal and spatial limits. This nature of online education has required educators around the globe to understand the use of emerging technology, as different from when we imagine the use of emerging technology in the traditional classroom (Oliveira et al., 2019). Online education has grown exponentially over the past few years. The year 2020 has forced every higher learning institution and to some extent primary and middle schools (in the United States and globally) to offer remote learning, which was necessitated by COVID-19 pandemic closures. This situation is likely to take root and become part of education at the K-12 level and beyond. Allen and Seaman (2019) noted that online education was on the rise, and about thirty percent of students in higher education were enrolled in at least one or more online courses (include fully online courses and blended courses). In 2016, over six million students enrolled in distance online courses with an increase of $3.9 \%$ over the previous year (Allen \& Seaman, 2017). The growth rate of online learning may be attributed to the growth and use of technology as a means of instructional delivery for the majority of higher education institutions, rising tuition costs, and an evolving workforce seeking lifelong learning options (Allen \& Seaman, 2019). The online learner population is heterogeneous, comprising students who are mostly employed, goal-oriented, and self-directed, and younger students who are dynamic and responsive to technological innovations (Kumi- Yeboah, 2018; Kumi-Yeboah, Dogbey, Yuan, \& Smith, 2020). Furthermore, the growth of online learning in universities and colleges had witnessed a high trend of the diverse student populations (Petersen, 2015). The increasing diversity of students in online learning environments demand that instructors understand and recognize cultural differences of students and design the best instructional strategies to help meet the learning needs of all students (Parrish \& Linder-VanBerschot, 2010).

The twenty-first century has witnessed widespread adaptation and use of digital technology tools in online courses, which has made it necessary to question the impact it has on the educational experiences, engagement, and learning outcomes on students (Robinson \& Hullinger, 2008; Zhou \& Zhang, 2008). Duderstadt, Atkins, and Houweling (2002) stated, "When implemented through active, inquiry-based learning pedagogies, online learning can stimulate students to use higherorder skills such as problem-solving, collaboration, and stimulation" (p. 75). Online instructors and instructional designers are concerned about how multimedia technology tools influence the engagement and participation of culturally diverse learners in online learning (Eikenberry, 2012; Lin \& Tsai, 2016; Twinning, Heller, Nussbaum, \& Tsai, 2017; Wolf, 2012). In this study, we define digital technologies as electronic tools, systems, devices, and resources that generate and store data from teaching and learning. It also includes learning materials that use technology across curriculum learning areas with examples such as online games, multimedia, cloud computing, 3D printing, and mobile computing. Presently, identifying the primary digital technologies that promote educational experiences and achievements of culturally diverse learners in online education is understudied (Twinning, Heller, Nussbaum, \& Tsai, 2017). The purpose of this study, therefore, was to explore the use of digital technologies from the perspective of diverse learners in online learning environments at higher education and the challenges they face. We discuss the educational implications for online instructors and instructional designers. 


\section{Review of Related Literature}

\section{Digital Technologies in Online Learning Environments}

Different digital technologies are used in online teaching daily through the use of different digital technologies including computers, iPads, smartphones, etc. Chao and Roblyer and Doering (2010) found that multimedia tools such as audio, video, and hyperlink documents nested in PowerPoint slides present learning materials that stimulate the attention of students and encourage their thinking process.

Similarly, a study by Bean (2012) found that the use of Prezi provides users with the opportunity for students and instructors to edit slides online in collaborative learning environments. Conboy, Fletcher, Russell, and Wilson (2012) conducted a qualitative study that interviewed students about their opinions on Prezi use in online learning. Results revealed that Prezi was a useful digital learning tool for facilitating their learning process. According to Biasutti and El-Deghaidy (2012), wikis has a positive impact on students' educational success in online learning, support students' thinking skills (Donnelly \& Boniface, 2013) as well as promote management skills. Miyazoe and Anderson (2010) conducted a study that investigated comparisons of three online writing activities in a university course: forums, blogs, and wikis. Results showed that students were more favorably disposed towards wikis $(86 \%)$ followed by blogs $(82 \%)$, and forums $(78 \%)$. The use of blogs was used as a writing material while wikis was associated with translation and beneficial in online collaborative learning activities.

According to Bryer and Zavattaro (2011), social media tools facilitate social interactions, which encourage collaborations and negotiations across multiple people. Furthermore, studies found that social media tools promote educational technologies that enhance peer feedback, students mentoring, and social interaction of learning (Alwagait, Shahzad, \& Alim, 2015; Dabbagh \& Kitsantas, 2012; Grosseck \& Holotescu, 2011; Sanch, Cortijo, \& Javed, 2014). Likewise, AlAufi and Crystal (2015) conducted a study that investigated the impact of social media on the academic patterns of informal communication between students in the social sciences and humanities. Findings indicated that social media tools had a positive effect on students' informal learned communication.

Interactivity is a critical component that digital technologies and teaching practice pursue. The popularity of synchronous video conferencing is partly based on its high interactivity among participants. The development of breaking out-rooms function enables instructors to organize group activities during video conferencing readily, but instructors are recommended to mobilize the structured guideline for promoting achievement. Saltz \& Heckman (2020) conducted a study about the effect of the combination of synchronous video-based break-out rooms and structured pair activity within online courses about programming. In a guided instruction of activities, students took alternately two roles: driver (the person that had control of the shared screen and was typing within a shared document) and observer (the person that saw what was being written by the driver). Findings from observing and surveying 114 break-out room sessions before and after the introduction of structured guidance showed improved coordination, expanded responsibilities, increased engagement, and productivity.

Bledsoe (2013) conducted a study that used multimedia tools (videos and audio clips). The study explored the implementation of a photo-rich comprehensive counseling center environment through which students of a semester-long online graduate psychology class learned about important research methodology concepts. Findings indicated that multimedia tools as an effective 
way to promote student learning and engagement in online settings. Hernández-Sellés et al. (2019) reported the positive relationship between the use of online collaborative tools (virtual campus, chat, and discussion forum) and the interactions within and between student groups. The use of VoiceThread, an online tool also allowed (students) users to record narration in presentation slides while they uploaded Power Point, was an illustrative example of emerging technology to enhance social presence (Thompson et al., 2017). Wang et al. (2020) demonstrated that instructor-present video, compared to instructor-absent video, had a better favorable effect on the learning process than otherwise. Young \& Hyunjoo (2020) studied the effect of interactive visual learning tools by comparing to the effect of noninteractive learning tools in an online course about color theory. The students who studied through a noninteractive learning tool $(n=21)$ used a webpage with written information and still image, and the students who studied through an interactive learning tool $(n=$ 24) interacted with an embedded interactive flash object that changed following students' input. The result showed that an interactive learning tool led to higher achievement than its counterpart in all areas (Control, Attention Focus, Curiosity, Intrinsic Interest, Intrinsic Motivation, and Extrinsic Motivation).

Furthermore, Stone \& Logan (2018) explored the experience of graduate students who use the social network site WhatsApp as an informal learning space. While teaching the online course to three cohorts (cohort A: $n=29$, cohort B: $n=23$, cohort $\mathrm{C}: n=21$ ), the researchers gathered data through focus group interviews for cohort A and the online survey for all cohorts. These students fostered a sense of connectedness by using WhatsApp. Results indicated that the benefits of using WhatsApp resulted from the freedom of the 'back channel' structure rather than the affordances and design of this social networking service (SNS) technology. However, distractions from using the SNS and overreliance on the SNS for course information were suggested as a risk. Moreover, various digital tools influence the level of interaction and have impacts on students learning, cross-cultural collaboration, and achievement in online learning.

\section{Teaching Diverse Learners in Online Learning Environments}

Regarding diverse learners' online learning experiences, Rovai and Ponton (2005) explored 108 African American and Caucasian graduate students' online experiences. They found that African American graduate students posted few discussion items or responses on discussion boards compared to Caucasian students, where they expressed a preference for auditory and visual communication threads. Fogg, Carlson-Sabelli, Carlson, and Giddens (2013) found that African American students preferred to be the assimilator in the virtual community, in contrast to students of other ethnicities.

Heitner \& Jennings (2016) reiterated some of the challenges that teachers and students might face in an online learning environment because they came from different worlds, socially, ethnically, culturally, etc. These differences could pose challenges that might affect online teaching and effectiveness. They examined "the level of differences in culturally responsiveness and knowledge and culturally responsive practices." Their study highlighted that while faculty valued and recognized the importance of culturally responsive teaching, they also recognized their limited skills in addressing the need in their classrooms. They highlighted knowledge gaps about culturally responsive teaching knowledge and practices online. Their findings hinted to the need to provide adequate support for online faculty with diverse students.

Similarly, Kumi-Yeboah et al. (2016) investigated the relationship between minority students' use of technology, social media, the number of online courses, program of study, 
satisfaction, and academic performance. Participants in the study were a diverse student body as regards to age, gender, and educational level functioned at both undergraduate and graduate levels. Analysis of variance (ANOVA) and chi-square tests showed that satisfaction and use of social media had no relationship with the academic performance of participants. However, a relationship existed between the use of technology, the number of courses in online learning, program of study, and academic performance. Categories that emerged from the open-ended questions were flexibility and time convenience, self-confidence, lack of support, self-regulated learning skills, and language and linguistic differences. The study concluded that varying factors such as cultural, language, personal, and efficacy skills facilitated the academic performance of minority students in an online learning environment. This study called on instructors to include multicultural contents in online courses and use the best pedagogical methods of teaching minority students in an online course.

Further, Mittelmeier et al. (2018) found that sociocultural factors such as cultural background and social network circles influenced participation when students worked online with peers from other countries. Sadykova \& Meskill (2019) pointed out that there were challenges in presenting online courses for diverse students from different cultures and countries. Through examining one international student journey and her experiences with her online course instructor, they pointed to the importance for online instructors to create space for specific culturally knowledge in their online courses considering the diversity represented in their online classrooms. Online instructors recommended the integration of cross-culture discussion at every opportunity and tolerance to language diversity to ensure course effectiveness for all students. Another study by Martin and Bolliger (2018) pointed out the importance of creating engaging activities in an online learning environment. They examined engagement strategies that learners perceived important in enhancing their learning in the online environment. Their study reinforced the importance of teacher-to-student, student-to-student, and student-to-content engagement strategies, with student-to-teacher being valued the most.

Kumi-Yeboah et al. (2020) conducted a study that examined online instructors' perceptions of cultural diversity in the online classroom and the challenges encountered by instructors of online courses as they incorporate multicultural learning content into the online learning environment. The study used Bennett's (2001) framework of multicultural research that explored cultural issues and how they affected the teaching and learning process in the face-to-face classroom. Participants included 50 instructors of online courses from three universities in the northeastern part of the United States who participated in the study. Findings showed that differential perceptions of cultural diversity existed among instructors of online courses: perceptions of cultural diversity depended on the academic disciplines taught by instructors; used variety of instructional strategies such as collaborative online learning activities, incorporating multicultural learning activities and global learning content, using cultural awareness project, addressing the impact of multicultural education; support cultural diversity in the online environment; and they also faced challenges associated with promoting cultural diversity in online teaching and learning.

However, these studies failed to recognize how digital technologies facilitate the educational experiences and achievements of diverse learners in online learning. Additionally, little research has been conducted to explore how the use of digital technologies from the perspective of diverse learners in online learning environments. Therefore, this study is intended to fill the gaps of knowledge regarding the use of digital technologies from the perspectives of diverse learners in online learning environments. 


\section{Conceptual Framework}

This study is primarily framed in the context of constructivism and collaborative online learning. Within the context of online constructivism, learners construct knowledge based on their cultural experiences, their situations, and their perspectives. Cultural constructivism encourages instructors to value the cultural perspectives and strengths of all learners in online learning environments. Online collaborative learning encourages students to share, participate, contribute, and discuss information. For example, Goodfellow and Lamy (2009) pointed out the challenges of constructivist theory in online learning are that the instructors may not understand the cultural backgrounds of students as well as the cultural experiences they bring to the online learning environment.

According to Havard, Du, and Xu (2008), Shi, Frederiksen, and Muis (2013) culture in online collaborative learning is considered one of the most critical factors that can help shape students' perceptions of the collaborative process, communication, and behavior in the group. Collaborative learning provides opportunities for students to create and refine their understanding to engage in the construction of knowledge in online discussion (Author, 2017). Studies by Balakrishnan, 2014, Bereiter \& Scardamalia, 2006, and Jonassen, 2006 found that computersupported collaborative learning (CSCL) provided an opportunity for students to create a new social related knowledge-building structure to help them to be part of the knowledge creation process in the online learning environment (Author 1, 2018). However, Kreijns, Kirschner, and Jochems (2003) found that not all students make a meaningful contribution to the knowledge building process. Thus, the theoretical frameworks described above were chosen to situate and guide this study.

\section{Research Questions:}

The study addressed the following research questions:

(1) How do culturally diverse learners describe how the use and application of digital technologies impact on their educational experiences and achievements in online learning environments?

(2) How do culturally diverse learners describe the use and application of multimedia presentations in online learning?

(3) How do culturally diverse learners describe the challenges they encounter in online learning environments regarding the use and application of digital technologies in online learning?

\section{Method}

In this study, qualitative research methods (Plano Clark \& Creswell, 2018) were used to explore the use of digital technologies from the perspective of diverse learners in online learning environments. We also conducted in-depth semi-structured interviews with participants. The qualitative research design allowed us to collect and analyze data about how digital technologies promote the educational experiences and achievement of diverse learners in an online learning environment. In the following sections, we provide descriptions of participants, data collection and analysis procedures, and findings. 


\section{Participants}

Participants consisted of 46 diverse undergraduate college students attending a comprehensive university in the northeastern part of the United States. Students included 22 males and 24 females with ages ranging from 20 to 24 years at the time of the interview. The sample was diverse regarding age, ethnicity, gender, academic level, and cultural background. Participants consisted of 18 African Americans, 14 Hispanics, 10 Asians, and 4 others. Additionally, participants were recruited from the programs of Education $(n=14)$, Engineering $(n=10)$, Social Sciences $(n=10)$, Health Sciences $(n=7)$, and Physical Sciences $(n=5)$. All participants had taken more than three online courses and had experiences of participating and engaging online activities.

\section{Recruitment and Data Collection}

We used stratified random sampling via the selection of participants from different academic programs (Education, Engineering, Social Sciences, Health, and Physical Sciences). Participants came from diverse backgrounds based on their ethnicity, sociocultural experiences, and backgrounds. First, we contacted the offices of the multicultural student affairs and international students after approval from the Institutional Review Board (IRB). Second, the first researcher contacted participants (60 in total) via email regarding the purpose of the research and asked for their participation. Third, 53 participants responded to the initial email expressing their willingness and agreed to participate in the study. Fourth, participants who agreed to participate in the study signed consent forms and gave consent to be interviewed. Lastly, we contacted participants via email and scheduled interview date and time at their convenience from which 46 students agreed and participated.

\section{Data Collection}

Before data collection, we conducted a pilot study (interviews) to test the interview protocols. Overall, the first author interviewed ten minority students regarding the use and application of digital technologies that enhance their educational experiences and successes in online learning. Results of the pilot study showed that digital technologies such as (blogs, wikis, eBooks, virtual conferencing, Google Hangouts/Docs, clickview, etc) facilitated the participation and knowledge construction among diverse learners in online learning. We then conducted semistructured and in-depth 60 to 90-minute interviews with participants from June 2019 to December 2019. Interview questions centered on how digital technologies influenced participants' educational experiences, the use of digital technologies, how digital technologies promoted their engagement and participation in online learning, communication with instructors and peers, and challenges encountered using digital technologies in online learning environments (see Appendix A). All interviews were conducted in English language and audio taped. Pseudonyms were used to identify all participants in reporting of the results to maintain participants' confidentiality.

\section{Data Analysis}

Analysis of the data was done by the research team via an extensive read-through of all transcripts (interviews), transcribed and checked for accuracy using the constant comparative method (Charmaz, 2006) with the aid of the qualitative software Nvivo (2017). The Nvivo software facilitated in the audit trail (e.g., the process of data collection and coding procedures) of our data analysis. The audit trail consisted of coded interview transcripts (e.g., memos). We used the theoretical framework of this study, "context of constructivism and collaborative online learning and the research questions" to guide the coding process in exploring digital technologies 
that promote educational experiences and achievements of diverse learners in online learning environments (Charmaz, 2006; Creswell, 2011). We carefully evaluated participants' interview transcripts and statements to help realign the data into coherent and orderly categories (Corbin \& Strauss, 2007). We analyzed the data with the assistance of a research assistant. We also met as a research team to deliberate, examine, address, and debate initial identified codes and categories. We held consistent discussions and finally reached an agreement through the constant comparison thematic analysis process.

Based on our theoretical framework and related literature in the field, we developed a list of codes during the initial analysis. Independently, each of the four researchers (three faculty members, and one graduate student assistant) in this study selected, coded, and analyzed the data, after which the team met to deliberate and negotiate the various category of codes identified. As a team, we reached an agreement through the constant comparison thematic analysis process (Leech \& Onwuegbuzie, 2011). We also carefully examined many transcripts from the interviews that had similar meanings before labeling a theme (e.g., digital tools, use of videos in online learning, the inclusion of technology in online environments, how to use digital tools, digital tools, and communication in online settings, digital tools and educational achievements, and benefits of digital tools in online learning). We checked data to find out if additional excerpts from interviews change the meaning of data. We refined data by removing redundant information and reexamining themes via member checking (Lincoln \& Guba, 2000). The first stage of data analysis yielded four major themes: (a) The influence of digital technologies that promote positive educational experiences with sub-themes (i) video lectures, (ii) voice thread, (iii) blogs/blogging, (iv) wikis, and (v) Google Hangouts; (b) The influence of multimedia presentations and online learning experiences with sub-theme (i) Powerpoints and Prezi; (c) The influence of social network tools and online learning, and; (d) challenges to include (i) lack of multicultural content resources and readings. Overall, the major themes were then developed from the categories and compared with the themes selected by the peer reviewers. Finally, we contacted all of the participants to obtain their views regarding the interview transcripts and to authenticate the credibility of the interpretations via member-checking (Merriam, 2009). They were also allowed to review interview transcripts to make changes to the contents of interview transcripts (Lincoln \& Guba, 2000). All these were done to reduce all biases and increase the reliability of the data.

\section{Results}

Data analysis produced the following themes: (a)The influence of digital technologies that promote positive educational experiences with sub-themes (i) video lectures, (ii) voice thread, (iii) blogs/blogging, (iv) wikis, and (v) Google Hangouts, (b) The influence of multimedia presentations and online learning experiences with sub-theme (i) Powerpoints and Prezi, (c) The influence of social network tools and online learning, and (d) Challenges to include (i) lack of multicultural content resources and readings.

\section{The Influence of Digital Technologies that Promote Positive Educational Experiences}

Most of the participants, 89\% (41 out of the 46) reported that use of digital technologies advanced their knowledge acquisition in the online learning environment. They referenced technology as learning tools that helped them to engage, participate, and contribute to knowledge creation in the online discussion forums. Participants mentioned digital technology devices such as video presentations, video lectures, voice thread and video chat, blogs, Google Hangouts, Wikis, 
audio-visuals, and other digital resources in the Learning Management Systems (LMS) that provided them opportunities to participate in the educational process in the online learning environment.

\section{Video Presentation.}

Most of the participants, $87 \%$ (40 out of the 46) indicated that video presentations helped them to connect with the learning content, particularly the examples shown. Steve, a participant from education, noted: "Video presentations help me to understand the concept or topic in online learning, I get to see visual examples and representations. It provides the chance to connect with instructors and colleagues and it makes online classroom looks like a traditional face-to-face one." Steve's statement is a reflection of how video presentations influence participants' educational experiences in online learning. As diverse learners, the use of video presentations helped them to connect to learning materials presented in online learning environments to enhance their academic achievements.

\section{Video Lectures.}

Participants explained that video lectures provided them additional resources, particularly instructors' directions and course expectations on assignments, project work, and group work. Bernice, a student studying social sciences commented by describing the benefits she gained from video lectures.:

Video lectures help me to connect to the instructor and build on my understanding of the topics I learned in an online classroom. Video lectures provide illustrations and experiences just like in the traditional face-to-face classes. Video lectures provide additional information regarding questions I have for the instructors ... such as instructions and contents. I think, these helped me to achieve better academic success in online learning.

Bernice described how video lectures presented an overview of the instructions and content resources. Participants reported that video lectures offered them a rich source of extra information regarding ways for them to engage with course information and directions. It also promotes the development of teaching presence for them.

\section{Voice Thread and Video Chat.}

A significant number of study participants, $80 \%$ (37 out of the 46) indicated that the use of voice thread and video chat helped to facilitate the development of personal connections with their peers and instructors in the online classrooms. Further, most participants revealed that voice thread provided them opportunities to upload images, videos, and record audios regarding project presentations and discussions, which helped them to understand topics. Mossa, a participant from the sciences noted: "Voice thread provides an avenue and chance to express your voice and contribute to online discussions just like in the face-to-face classroom" Mustapha a participant from education, shared:

Yes, using voice thread in the LMS has helped me to connect with my course mates and instructors. It provides me the chance to respond to questions from videos posted by both students and instructors. Voice thread allows you to create a virtual tour of a historical place, analyze and comment on photographs. It helps to connect or say relate to the course materials and be active in all class discussions. 
Participants' statements indicated that the use of voice thread promoted students' collaborative knowledge building and created the opportunity for them to express, share, and contribute to knowledge creation in an online learning environment. Elsie, a participant from social sciences, noted: "Voice thread helps me to understand presentations better because of the visual aspect of it. I like the fact you use both audio and video in presenting your project." Participants elaborated that voice thread served as an interactive digital tool that enhanced their engagement and contributions to dialogue about videos, documents, articles, and John, a participant from engineering, elaborated:

Voice thread in LMS has the potential to motivate you to engage and participate in all online class activities or projects and contribute to online discussions. It also allows me to connect and build on my social interactions with instructors and peers.

Most of the participants agreed that the use of voice thread helped them to be engaged, motivated, and independent learners in the online environment, an experience, to which most participants attributed their academic achievements in online education.

\section{Blogs/Blogging.}

The majority of the participants $87 \%$, (40 out of the 46) confirmed that the use of blogs in the LMS helped them to respond to discussion posts that would not have happened in face-to-face classrooms. Participants' responses confirmed that blogs in online learning serve as an effective tool for small group assignments, which promote collaborative learning. For instance, Shaun, a participant from health sciences described his experience using blogs in the online course, saying, "blogging or blogs served as a reflective tool to reflect on course readings and discussion posts or projects to prepare for the final exam." Further, Shaun's comment reflects the views of many participants that the use of blogs in the LMS provided them with the opportunity to collaboratively share and create knowledge. Most participants $82 \%$, (38 out of the 46) also expressed that the use of a blog in an online setting helps students engage in large group discussions because it provides the opportunity for all students to communicate, share, and participate in a meaningful discussion. Participants stated that blogs/blogging in online courses makes it easier for them to submit assignments. Blogs also serve as a knowledge-building interactive tool to help participants understand the topics being discussed. Maxi, a participant from social sciences, commented:

The use of blogging in my online course promotes my critical and reflective thinking skills and the creation of ownership of ideas. I feel like I'm part of the knowledge produced and can regulate my ideas in what to express and put it online. There is always the motivation to respond to other posts on the blog at any time and really like that format because it gives me ample time to think and make a contribution to class discussion or group activities.

Another participant, Mary from education emphasized that the use of blogs helped her to understand and contribute to knowledge creation in the online classroom. She noted: "Using blogs or blogging in the online course provides me instructional resources as instructors can post hyperlinks to websites that give information and resources on how to complete assignments." Most participants, 85\% (39 out of the 46), expressed that the use of blogs provided communication and collaborative tools that helped them to contribute and express their ideas, as did receiving positive feedback from others. Participants indicated that blogs facilitated knowledge sharing between students and the ability to discuss real-world issues helped them link knowledge from theory to practice. 


\section{Wikis.}

According to Biasutti (2017), wikis are Web 2.0 tools for writing online text in collaboration. Students use wikis as collaborative interactive tools to communicate and connect with the course content in online classes. Participants indicated that wikis served as databases for course information concerning written texts and comments to questions, assignments, and/or projects, in which they could easily and make changes and manage multiple versions of texts. Edward, an engineering student, elaborated: "Using wikis has helped me in all online courses I have taken, it serves as a data storing tool for you to monitor course content resource information." Another participant, Sheila, from health sciences stated:

In two of the online courses I have taken, the instructors made us use wikis as a discussion forum, Wikis allows you to become part of the knowledge construction process and easy to format the pages. It is very convenient as you link wiki pages to other external sites for other students to read more about your project or assignments. The collaborative nature of wikis helped me to understand the content of that course and had an excellent grade.

According to $\mathrm{Ng}$ (2016), a wiki learning environment helps students develop knowledge collaboratively via the sharing of ideas and thoughts and promotes students' metacognitive skills. Participants agreed that are an open technology tool that allow students to set up, change, or remove information at any time. Overall, participants agreed that wikis helped them engage and participate in small collaborative group projects.

\section{Google Hangouts.}

Participants agreed that Google Hangouts helped them to communicate within a large group. It also served as a digital tool to connect them with other students and engage with the course content. They reported that the Google Hangout tool helped them to communicate with instructors at least once a week to seek guidance on assignments or projects. Sam, a participant from sciences, noted: "I think 'Google Hangouts' brings the social presence part of online learning because it allows you to communicate and interact with instructors and peers... to ask questions and get feedback." Another participant described his experience using Google Hangouts, saying:

Google Hangouts helps to communicate with peers and instructors. For instance, it helps you to connect with students and instructors on a personal level and to collaborate with group members to discuss with other students regarding assignments or group projects. This digital tool gives me the flexibility to achieve better educational experience in online learning.

The above statement showed that Google Hangouts made learning more engaging and personalized because it made communication and collaboration easier outside the online classroom. Participants also reported that using the Google Hangout tool helped them to network with each other.

\section{The Influence of Multimedia Presentations and Online Learning Experiences}

Multimedia technologies play an important role in student engagement and participation in online discussion. For example, Leila, a participant from education described her experience and use of multimedia tools saying: 
Yeah... multimedia tools have helped me to share videos, presentations, and post audio files to other students and instructors to view and provide comments and it brings the personal connection that is in online learning environments. Again, multimedia tools help me to collaborate with instructors and other students regarding course content and performance.

The majority of the participants, $89 \%$ (41 out of the 46), responded that multimedia presentations facilitated their participation in online learning. For instance, Mana stated: "multimedia presentations enhance my engagement in an online learning setting. Because some of the examples meet my learning needs culturally by providing a medium for creating, sharing, and ability to collaborate on online presentations." Most of the participants, $87 \%$ (40 out of the 46), agreed that multimedia technologies enhanced their ability to create and share videos and audios regarding project presentations online. Participants stated that the visual components of multimedia helped them to understand course content and engage in online discussions. Peter, an engineering student, had this to say about his experiences using multimedia tools, "Multimedia tools give you access to course materials in electronic formats such as audios, videos, and other visuals. You get to learn in an unstructured format." For example, participants expressed that the use of audio narration helped them to understand course content and helped them to connect content to real-life experiences. As one participant stated: "the use of multimedia tools provides you with practical learning that you can relate to course content."

\section{PowerPoint and Prezi.}

The majority of the participants reported that PowerPoint presentations organized course content into smaller pieces that summarized concepts in an organized order for the class. Most participants, $84 \%$ (39 out of the 46), stated that PowerPoint presentations helped to convey the main ideas of the course to other students and instructors. Kathy, a participant from education, noted: "PowerPoint presentation summarizes everything for you regarding course contents. It also stimulates my thinking process in knowledge acquisition in online classrooms." Sanachi, a participant from social sciences elaborated: "PowerPoint notes help me to understand online course materials better especially PowerPoint add-in to record presentations makes it feel like in the face-to-face class." Participants revealed that PowerPoint presentations summarized course materials and made it easy to read them, which enhanced their learning achievement. They indicated that PowerPoint presentations provided a source of knowledge acquisition.

Another digital tool that most participants mentioned was Prezi. For example, Ashley, a participant from engineering stated:

I like Prezi over PowerPoint because it has many screen animation functions that help me to illustrate and organize different graphics and concepts with words. It is also innovative as you can sequence or show slides in spiral sequencing, which influence my learning in the online environment.

Most of the participants, $83 \%$ (38 out of the 46), reported Prezi to be a useful digital learning tool that facilitated educational experiences in online learning. It also helped them to present their projects in ways that helped other students and instructors to understand learning materials in the LMS. 


\section{The Influence of Social Network Tools and Online Learning Experiences}

In the twenty-first century, the use of social media and networking tools has shaped information communication and technology use in online learning environments. Participants agreed that social media networks created collaborative learning environments that reinforced their learning. According to Ruleman (2012), social media provide students efficient communication, collaboration, and connection that positively influence learning. For example, De-Silva from the sciences reported that the use of social media networks in online learning helped her to be an active learner and participate in online discussion and provided her with the opportunity to be part of the knowledge-building process. She commented:

Social media supports my online learning because it is the medium through which most instructors use to remind students about assignments, announcements, due dates for assignments or group projects, and other emergencies. For example, social media gives direct interface and a convenient time to pose questions for your peers to respond and serves as a collaborative learning tool to share ideas on concepts of what we learn.

The majority of the participants, $91 \%$ (42 out of the 46), agreed that social media networks (notably, YouTube) provided visual information and educational resources that enhanced their collaborative learning in the online learning environments. Participants agreed that YouTube offered them educational resources including visual and video explanations of concepts as well as opportunities for peer feedback and exchange of ideas. For example, Amir, a participant in the health sciences shared:

I took a statistics course, and the instructor did a great job of creating video links to view clips to help students understand concepts. It provided valuable videos explaining the concepts, and it helped me to get an excellent grade in that class. Other students posted additional videos on Facebook to share information and ideas on topics we discuss in online discussions.

Participants emphasized the importance of social media as a means of promoting creative thinking and collaborative learning via the sharing of digital information. They expressed that Facebook provides the most additional information to support their educational experiences regarding communication, collaboration, and resource sharing in the online learning environment. Most participants, 91\% (42 out of the 46), indicated that social media offered them better communication media, access to resources and information, personal interactions with peers, resource persons in videos, and the ability to be part of the knowledge creation.

\section{Challenges}

\section{Lack of Multicultural Content Resources and Readings}

The use and application of digital technologies in online learning come with some problems. The majority of the participants, $84 \%$ (39 out of the 46), reported facing challenges including the lack of multicultural content and instructor support on how to use digital technologies, which affected their educational experiences and success in online learning. For instance, Rubashi, a participant from the health sciences commented:

Most of the readings in my online courses lack examples that I can relate to help me understand the topic or concept. The content of course materials are of European or American backgrounds, and it's like this is it take or leave it. I don't have an 
opportunity to contribute my thoughts or ideas based on my cultural and social experiences, I mean from my perspectives. You know if the readings are not fun, you become less motivated to engage and participate in a discussion.

Similarly, Taskhi, a participant from education described his challenges in online education, saying, "well, as a minority student, I face challenges of reading materials that I can hardly relate to, especially the examples in most articles I read are out of touch for me to relate. Hence, making it hard to engage in-class activities." Both participants advocated for instructors to incorporate culturally relevant reading materials to help them engage and participate in knowledge construction. Participants also mentioned a lack of support from instructors on how to use some of the digital technologies in their online courses. For example, Zhao, a participant from engineering stated: "I had no orientation on how to use and apply some of the digital technologies instructors required us to use in online courses. There was no instructor support, which affected my learning in an online context."

\section{Discussion}

This article explored how digital technologies enhance the educational experiences and achievements of ethnically diverse learners in online education. It also examined the challenges culturally diverse learners encounter regarding their academic achievement in online education. In doing so, the article aimed to explore digital technologies that promote the educational experiences and academic achievements of culturally diverse learners in online learning. Overall, the study found four major themes namely (a) the influence of digital technologies that promote positive educational experiences with the sub-themes (i) video lectures, (ii) voice thread, (iii) blogs/blogging, (iv) wikis, and (v) Google Hangouts; (b) the influence of multimedia presentations and online learning experiences with the sub-themes (i) Powerpoints and Prezi; (c) the influence of social network tools and online learning, and; (d) the lack of multicultural content resources and content.

Findings demonstrated that the use of digital technologies positively influenced the online learning experiences and the academic achievements of participants. For example, participants reported that the use of digital technologies in the LMS supported consistent interactions with course content, students and instructors, and helped them to engage and participate in the knowledge-building process in online courses. Participants reported that technologies in the online LMS such as video lectures, voice threads, blogs, and wikis provided them opportunities to communicate with instructors and peers, and have more access to course resources, which helped them to achieve better educational performance. They emphasized that digital technologies offered them a space to make project presentations, communicate with other students and instructors via video chats, and exchange ideas via voice thread, which facilitated collaborative learning and motivated them to be part of the knowledge creation process. Other participants revealed that the use of digital technologies helped them improve their writing skills. It provided opportunities to organize and store information in collaborative group activities. These findings are consistent with prior studies (Kear et al., 2010; Kumi-Yeboah et al., 2017) that reported that digital tools such as wikis, and forums support the collaborative learning activities of students in online learning environments, and blogs or blogging also helped students' writing skills (Twinning, Heller, Nussbaum, \& Tsai, 2017). 
Furthermore, findings demonstrated that multimedia presentations helped facilitate participants' online learning experiences and educational achievements. Participants indicated that multimedia presentations such as PowerPoint slides and Prezi provided them opportunities to create information using these technologies to summarize course information. According to Bledsoe (2013), multimedia tools such as audio, video, and hyperlink documents embedded in PowerPoint slides present learning materials that stimulate, motivate and encourage students' thinking processes. Another finding of this study was that multimedia presentations in LMS environments promoted the collaborative learning experiences of diverse learners which helped them to achieve better educational outcomes. It also provided course resources and an array of information to support knowledge building and creativity.

Moreover, findings demonstrated that social network tools helped participants to create collaborative learning environments and to develop teamwork skills necessary for success in computer-supported collaborative learning. These findings support collaborative learning theory in that such tools provide students the opportunity to create a new knowledge-building structures to help them play an active role in the knowledge creation process (Balakrishnan, 2014; KumiYeboah, 2018). According to Ruleman (2012), social media provide students with efficient communication, collaboration, and connection that positively influence knowledge acquisition. Findings in this study are consistent with constructivist theory and suggest that learners from diverse social and cultural backgrounds can construct knowledge from their cultural and educational experiences.

The findings above are in line with the constructivist view of learning. According to Vygotsky (1978), learning occurs through interaction between one person and another. As Lee and Smagorinsky (2000) put it, "learning is mediated first on the inter-psychological plane between a person and other people and their cultural artifacts, and then appropriated by individuals on the intra-psychological plane" (p. 2). The online teaching tools provided a space for different forms of scaffolding through the use of the online platforms (course concepts and materials, digital tools, media presentations, social networks, etc.) as mediational tools in the process of knowledge construction. These digital tools positively influenced participants' learning and engagement.

On the other hand, the study showed that participants faced challenges concerning the of lack of multicultural content and readings in the online learning environments in ways that affected their academic success. Participants stated that resources and readings lacked cultural examples to which they could relate to help them contribute to the knowledge building process. Findings support the research (Kumi-Yeboah, 2018) that most online learning courses are designed with a lack of culturally relevant content to help address and support diverse learners' needs. Participants also expressed facing the challenge of a lack of instructor support regarding the practical use of digital technologies in online learning. Thus, instructors and designers should support the metacognition of diverse learners by incorporating examples of students' prior work, multiple content presentations infused with multimedia presentations to help diverse learners in an online context (Ashong, \& Commander, 2012; Li, 2012). Online learning environments should be inclusive and support diverse groups of learners (Ke \& Kwak, 2013).

The present study extends on previous research on exploring the use of digital technologies from the perspective of diverse learners in online learning environments in several ways. First, this study is an attempt to better understand digital technologies that promote the educational experiences and achievements of diverse learners in online education, which addressee a critical research gap in the literature (Lin \& Tsai, 2016; Twinning, Heller, Nussbaum, \& Tsai, 2017). 
Second, the findings showed a growing need for online instructors to infuse digital technologies in online teaching to help support diverse learners' educational achievements. The study also seeks to broaden online instructors' understanding of how best to use digital technologies to provide authentic and meaningful learning experiences for diverse learners. Finally, the study provides valuable information about the use of digital technologies in online learning and how they help diverse students to set their own learning goals, manage their learning, and communicate with others.

\section{Recommendations}

Several recommendations resulted from the present. Considering the increasing growth of diverse student populations in online learning, instructors need to include digital technologies that promote the educational experiences and achievements of diverse learners. Therefore, instructors need to recognize the cultural backgrounds of students in online classrooms, and the need to provide them with digital technologies to help them better understand course content and contribute to knowledge creation in online learning environments. Another important recommendation of this study is to inform online instructors and instructional designers to be cognizant of the various digital technologies that are available to use or adopt when designing online courses, specifically those that support students from diverse backgrounds.

\section{Implications}

This study highlights digital technologies that influence the educational experiences and achievements of culturally diverse learners in online learning. It also demonstrates that incorporating digital technologies in online learning promotes the educational achievements of culturally diverse learners. These findings extend prior research that found that digital technologies offered students the opportunities to engage, share, reflect, and participate in online collaborative group work to become part of the knowledge building process (Biasutti \& El-Deghaidy, 2012; Kear et al., 2010; Roblyer \& Doering, 2010).

\section{Limitations}

Our findings were based on the experiences of 46 diverse learners that used digital technologies in online courses at a single university. Moreover, technologies change very quickly, thus the research only represents findings from a particular place and time and cannot necessarily be applied to other settings and times. Given the heterogeneity of students in online learning, future research could look into a quantitative study on how digital technologies facilitate the educational achievements of diverse online learners. Findings will inform online instructors to better recognize and understand how to attend to the cultural differences and cultural knowledge these learners bring to the online environment and devise learning strategies to meet their needs.

\section{Conclusion}

The inclusion of digital technologies in online learning environments help students from diverse backgrounds to understand and contribute to knowledge construction, engagement, and academic achievement. Vygotsky (1978) emphasized the importance of the sociocultural context in learning. This implies that the sociocultural context of students in online learning should be taken into account in the choice of materials and applications to create a shared learning experience. The findings show that culturally diverse learners experience academic achievement via the use of digital technologies, in particular: (a) the influence of digital technologies that 
promote positive educational experiences such as (i) video lectures, (ii) voice thread, (iii) blogs/blogging, (iv) wikis, and (v) Google Hangouts; (b) the influence of multimedia presentations and online learning experiences including Powerpoint and Prezi, and ; (c) the influence of social network tools and online learning. At the same time they are challenged by (d) the lack of multicultural content resources and readings. This paper sets out to expand our understanding of the relevance of how digital technologies best promote the educational experience and achievement of diverse learners in online learning. Thus, online instructors should be cognizant of their students and include materials that are culturally relevant to create a rich learning environment for all learners.

\section{Notes}

1. We use pseudonyms throughout the study to represent student participants.

2. We define culturally diverse learners as students who are categorized in the United States educational systems as a result of their ethnicity, language acquisition, socio-cultural experiences, and cultural backgrounds. 


\section{References}

Al-Aufi, A., \& Crystal, F. (2015). Impact of social networking tools on scholarly communication: A cross-institutional study. The Electronic Library, 33(2), 224-241.

Allen, I. E., \& Seaman, J. (2019). Changing course: Ten years of tracking online education in the United States. Sloan Consortium.

Alwagait, E., Shahzad, B., \& Alim, S. (2015). Impact of social media usage on students academic performance in Saudi Arabia. Computers in Human Behavior, 51(2015), 10921097.

Ashong, C. Y., \& Commander, N. E. (2012). Ethnicity, gender, and perceptions of online learning in higher education. MERLOT Journal of Online Learning and Teaching, 8(2).

Balakrishnan, B. (2014). Online computer supported collaborative learning (CSCL) for engineering students: A case study in Malaysia. Computer Applications in Engineering Education, 1-11.

Bean, J. (2012). Presentation software supporting visual design: Displaying spatial relationships with a zooming user interface. In Professional Communication Conference (IPCC) (pp. 1-6). IEEE.

Biasutti, M., \& EL-Deghaidy, H. (2012). Using Wiki in teacher education: Impact on knowledge management processes and student satisfaction. Computers \& Education, 59(3), 861872.

Bledsoe, T. (2013). A multimedia-rich platform to enhance student engagement and learning in an online environment. Online Learning Journal, 17(4). https://www.learntechlib.org/p/183762/.

Bryer, T., \& Zavattaro, S. (2011). Social media and public administration: Theoretical dimensions and introduction to symposium. Administrative Theory \& Praxis, 33(3), 327 340 .

Charmaz, K. (2006). Constructing grounded theory: A practical guide through qualitative analysis. Sage.

Conboy, C., Fletcher, S., Russell, K., \& Wilson, M. (2012). An evaluation of the potential use and impact of Prezi, the zooming editor software, as a tool to facilitate learning in higher education, Innovations in Practice, 7, 31-45.

Corbin, J. M., \& Strauss, A. L. (2007). Basics of qualitative research: Techniques and procedures for developing grounded theory. Sage.

Creswell, J. W. (2011). Research design: Qualitative, quantitative, and mixed methods approaches (2nd ed.). Sage.

Dabbagh, N., \& Kitsantas, A. (2012). Personal learning environments, social media, and selfregulated learning: A natural formula for connecting formal and informal learning. The Internet and Higher Education, 15(1), 3-8.

Donnelly, D. F., \& Boniface, S. (2013). Consuming and creating: Early-adopting science teachers' perceptions and use of a wiki to support professional development. Computers \& Education, 68, 9-20. 
Duderstadt, J., Atkins, D., \& Houweling, D. (2002). Higher education in the digital age: Technology issues and strategies for American colleges and universities. Praeger.

Duran, E., \& Amandi, A. (2011). Personalized collaborative skills for student models. Interactive Learning Environments, 19(20), 143-162.

Fogg, L., Carlson-Sabelli, L., Carlson, K., \& Giddens, J. (2013). The perceived benefits of a virtual community: effects of learning style, race, ethnicity, and frequency of use on nursing students. Nursing Education Perspectives, 34, 390-394.

Eikenberry, A. M. (2012). Social networking, learning, and civic engagement: New relationships between professors and students, public administrators, and citizens. Journal of Public Affairs Education, 18(3), 449-466.

Goodfellow, R., \& Lamy, M. N. (2009). Conclusions: New directions for research in online learning cultures. In R. Goodfellow \& M-N. Lamy (Eds.), Learning cultures in online education (pp. 170-183). Continuum Studies in Education.

Grosseck, G., \& Holotescu, C. (2011). Academic research in 140 characters or less. Anywhere, anytime-Education on demand (Vol. II, pp. 84-94). [Conference presentation]. International Scientific Conference elearning and software for education, Bucharest, April 28-29, 2011. http://adlunap.ro/eLSE_publications/ papers/2011/1590_1

Havard, B., Du. J., \& Xu, J. (2008). Online collaborative learning and communication media, Journal of Interactive Learning Research, 19(1), 37-50.

Heitner, K. L., \& Jennings, M. (2016). Culturally responsive teaching knowledge and practices of online faculty. Online Learning, 20, 4, 54-78.

Jonassen, D. (2006). Modeling with technology: Mindtools for conceptual change (3rd ed.). Prentice Hall.

Ke, F., \& Kwak, D. (2013). Online learning across ethnicity and age: A study on learning interaction participation, perception, and learning satisfaction. Computers and Education, $61,43-51$.

Kim, K. J., \& Bonk, C. J. (2002). Cross cultural comparisons of online collaboration. Journal of Computer-Mediated Communication, 8(1). http://www.ascusc.org/jcmc/vol8/issue1/kimandbonk/html.

Kreijns, K., Kirschner, P. A., \& Jochems, W. (2003). Identifying the pitfalls for social interaction in computer supported collaborative learning environments: A review of the research. Computers in Human Behavior, 19, 335-353.

Kumi-Yeboah, A., Dogbey, J. K., Yuan, G., \& Smith, P. (2020). Cultural diversity in online learning: An exploration of instructors' perceptions and challenges. Teachers College Record. https://www.tcrecord.org/content.asp?contentid=23332

Kumi-Yeboah, A., (2018). Designing a cross-cultural collaborative online learning framework for online instructors. Online Learning Journal. 22(4), 181-201.

Kumi-Yeboah, A., \& Smith, P. (2016). Relationships between minority students' online learning experiences and academic performance. Online Learning Journal, 20(4), 1-28. 
Lee, C. D. \& Smagorinsky, P. (2000). Vygotskian perspectives on literacy research: Constructing meaning through collaborative inquiry. Cambridge University Press.

Leech, N. L., \& Onwuegbuzie, A. J. (2011). Beyond constant comparison qualitative data analysis: Using NVivo. School Psychology Quarterly, 26(1), 70-84. https://doi.org/10.1037/a0022711

Li, J. (2012). Cultural Foundations of Learning: East and West. Cambridge University Press.

Lin, C. L., Hou, H. T., \& Tsai, C. C. (2016). Analyzing the social knowledge construction and online searching behavior of high school learners during a collaborative problem solving learning activity: A multi-dimensional behavioral pattern analysis. The Asia-Pacific Education Researcher, 25(5-6), 893-906.

Lincoln, Y. S., \& Guba, E. G. (2000). Naturalistic Inquiry. Sage.

Martin, F., \& Bolliger, D. U. (2018). Engagement matters: Student perceptions on the importance of engagement strategies in the online learning environment. Online Learning, 22, 1, 205-222.

Merriam, S. B. (2009). Qualitative Research: A Guide to Design and Implementation. JosseyBass.

Mittelmeier, J., Rienties, B., Tempelaar, D., Hillaire, G., \& Whitelock, D. (2018). The influence of internationalized versus local content on online intercultural collaboration in groups: A randomized control trial study in a statistics course. Computers \& Education, 118, 82-95.

Miyazoe, T., \& Anderson, T. (2010). Learning outcomes and students' perceptions of online writing simultaneous implementation of a forum, blog and wiki in a EFL blended learning setting. System, 36(2), 185-199.

Okwumabua, T. M., Walker, K. M., Hu, X., \& Watson, A. (2011). An exploration of African American students' attitudes toward online learning. Urban Education, 46, 241-250.

Oliveira, A., Feyzi Behnagh, R., Ni, L., Mohsinah, A. A., Burgess, K. J., Guo, L. (2019). Emerging technologies as pedagogical tools for teaching and learning science: A literature review. Hum Behavior \& Emerging Technology, 1(2), 149-160. https://doi.org/10.1002/hbe2.141

Parrish P., \& Linder-VanBerschot J. A. (2010). Cultural dimensions of learning: Addressing the challenges of multicultural instruction. The International Review of Research in Open and Distance Learning, 11 (2). http://www.irrodl.org/index.php/irrodl/article/view/809/1497.

Perron, B. E., \& Steaens, A. (2010). A review of a presentation technology: Prezi. Research on Social Work Practice, 1-2.

Petersen, J. (2015). Honoring diversity in an online classroom: Approaches used by instructors engaging through an LSM [Doctoral dissertation, University of Nebraska-Lincoln]. ProQuest Dissertations \& Theses.

Robinson, C. C., \& Hullinger, H. (2008). New benchmarks in higher education: Student engagement in online learning. Journal of Education for Business, 84(2), 101e108. http://dx.doi.org/10.3200/JOEB.84.2.101-109. 
Roblyer, M. D., \& Doering, A. H. (2010). Integrating educational technology into teaching (5th ed.). Allyn and Bacon.

Rovai, A. P., Ponton, M. K., Wighting, M. J., \& Baker, J. D. (2007). A comparative analysis of student motivation in traditional classroom and E-learning courses. International. Journal on E-Learning, 6(3), 413-432.

Ruleman, A. B. (2012). Social media at the university: A demographic comparison. New Library World, 113(7/8), 316-332.

Sadykova, G., \& Meskill, C. (2019). Interculturality in online learning: Instructor and student accommodations. Online Learning, 23(1), 5-21. doi:10.24059/olj.v23i1.1418.

Saltz, J., \& Heckman, R. (2020). Using structured pair activities in a distributed online breakout room. 24(1), 227-244.

Scardamalia, M., \& Bereiter, C. (2006). Knowledge building: theory, pedagogy, and technology. In The Cambridge handbook of the learning sciences (pp. 97-115). Cambridge University Press.

Shi, Y., Frederiksen, C. H., \& Muis, K. R. (2013). A cross-cultural study of self-regulated learning in a computer-supported collaborative learning environment. Learning and Instruction, 23, 52-59.

Stone, S., \& Logan, A. (2018). Exploring students' use of the social networking site WhatsApp to foster connectedness in the online learning experience. Irish Journal of Technology Enhanced Learning, 3(1), 42-55. https://doi.org/10.22554/ijtel.v3i1.28

Twinning, P., Heller, R. S., Nussbaum, M., \& Tsai, C. C. (2017). Some guidance on conducting and reporting qualitative studies. Computers \& Education, 106, A1-A9.

Vygotsky, L. S. (1978). Mind in society: The development of higher psychological processes. Harvard University Press.

Wolf, M. M. (2012). Using social media for collaboration about industry news in higher education. American Association of Wine Economists 2012 AAWE.

Zhou, L., \& Zhang, D. (2008). Web 2.0 impact on student learning process. In K. McFerrin et al. (Eds.), Proceedings of society for information technology and teacher education international conference (pp. 2880-2882). AACE. 


\section{Appendix A}

\section{Exploring digital technologies that promote educational experiences and achievements of diverse learners in online learning environments}

1. Please tell me about your online learning experience. How has it been? Please describe in detail how you are enjoying it.

2. Describe your access to digital technology in online course.

3. Can you tell us about your experience using digital technology or technologies in online learning environment? How do you define that?

4. How do you use digital technologies to interact with students (peers) and instructors in the online learning environment?

5. Do you think the communication tools, such as emails, online chats, videos, and discussion board, have been useful for online learning collaboration? Why or why not? Please explain.

6. What other communication tools (such as Skype, videos) did your online course? Why did you choose to use those tools or what was your preference?

7. What type of multimedia technologies or presentations do you prefer? Why do you prefer this type? Describe how multimedia tool contribute more to your online learning experiences and educational achievements.

8. How would you describe your experience using digital technologies and how it facilitates your online collaborative learning activities and educational success? Please explain with examples.

9. Please tell me what type of social networking applications and or tools (e.g., Facebook, YouTube, Twitter, LinkedIn, and others) do you use in online learning and describe how it helps you to contribute and gain knowledge.

10. What are your primary reasons for using social networking applications in your online learning course and describe how it enhances your academic success?

11. Which of the digital and multimedia technologies motivates you to contribute or learn better in an online course? How did these technologies contribute to your educational achievements in online learning? Please explain.

12. Please describe the best social networking application tool that help or enhance your educational achievements in online course/learning. Explain with examples.

13. What are the benefits you gain from digital technologies and multimedia presentations online learning. Please explain with specific examples.

14. Describe the major challenges you face using digital and multimedia technologies online learning environments. Please provide specific examples.

15. How would you address cultural differences in the online learning environment? Do you want anyone to ask you questions about your cultural background or related to your background in online environments?

16. Do you think digital technologies helps you to succeed as a diverse learner in the online learning? Why or why not? Please explain. 